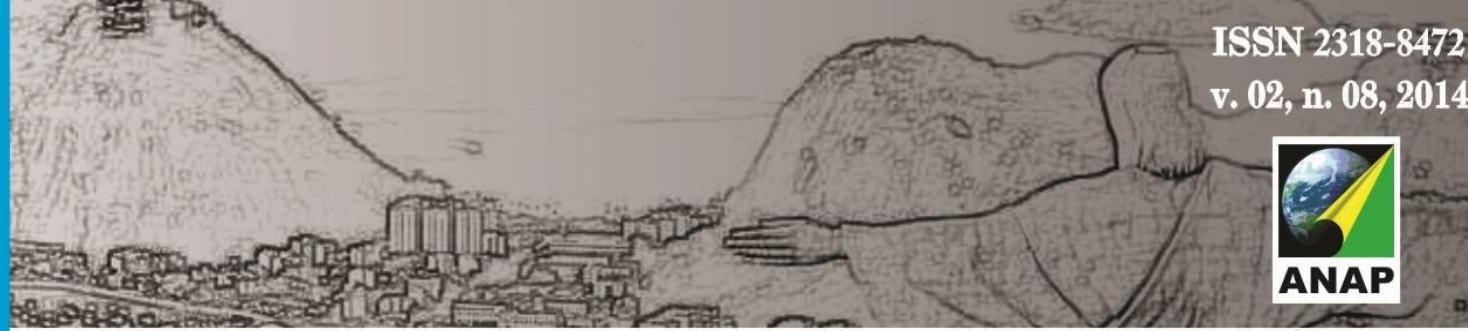

Revista Nacional de

Gerenciamento de Cidades

\title{
ENTRE METRÓPOLES: AGLOMERADO URBANO DE JUNDIAÍ
}

\section{Lacir Ferreira Baldusco ${ }^{1}$}

\author{
José Geraldo Simões Júnior ${ }^{2}$
}

\begin{abstract}
RESUMO
Localizado entre as duas maiores metrópoles brasileiras, São Paulo e Campinas, e inserido no complexo macrometropolitano paulista, o Aglomerado Urbano de Jundiaí tem se destacado pelo seu dinamismo sócio econômico e por sua expansão físico-territorial. Demonstramos esse dinamismo por meio dos índices migratórios que, de maneira muito clara, ainda figuram como protagonistas do crescimento populacional dessa região. Tendo, na figura do loteamento e do condomínio, instrumentos principais para o parcelamento do solo, o segmento habitacional do mercado imobiliário tem atuado como protagonista do processo de expansão da malha urbana. Temos nas áreas urbanas centrais mais valorizadas, um processo de verticalização através de condomínios, criando ilhas de riqueza. Em contrapartida, os loteamentos localizados nas franjas da cidade promovem o espraiamento da periferia, que ultrapassa os limites territoriais do município e invade o território vizinho, sujeitando o trabalhador a longos deslocamentos na cidade ou mesmo entre municípios. Portanto, as alterações manifestas no processo de expansão urbana no Aglomerado Urbano de Jundiaí não representam ruptura na organização socioespacial do território, ao contrário, consolidam tendências expressas na Região Metropolitana de São Paulo desde a sua formação, sobressaindo-se o contínuo processo de esgarçamento do tecido urbano por meio da hierarquização do seu território estabelecido por dinâmicas socioeconômicas com consequências físico-espaciais.
\end{abstract}

PALAVRAS-CHAVE: Macrometrópole; Urbano; Dispersão; Pendularidade; Habitação.

\footnotetext{
1 Arquiteto, Profo Mestre, Universidade Presbiteriana Mackenzie, Rua da Consolação, 930 Consolação, São Paulo - SP, 01302-907 - E-mail: lacirbaldusco@yahoo.com.br_-

${ }^{2}$ Arquiteto e Urbanista, Profo. Doutor, Universidade Presbiteriana Mackenzie, Rua da Consolação, 930 - Consolação, São Paulo - SP, 01302-907 - E-mail: arquitetura.pos@mackenzie.br
} 


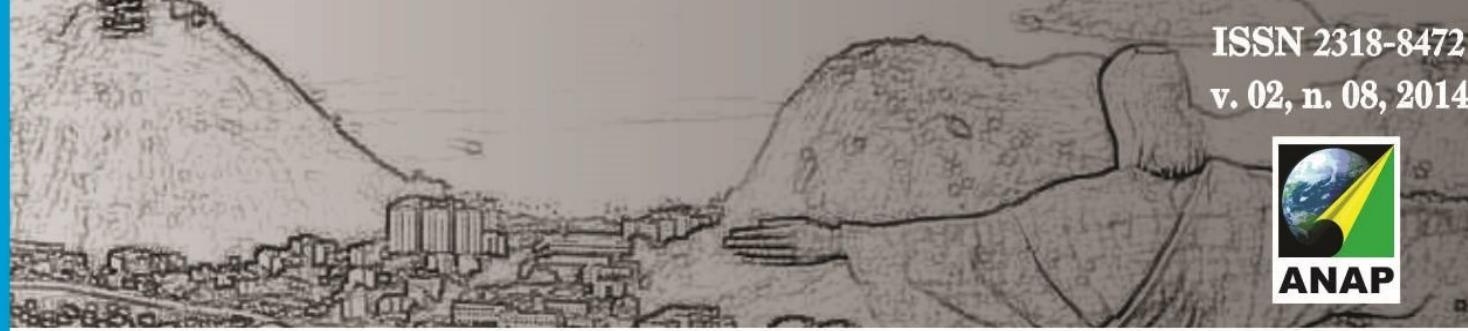

Revista Nacional de

Gerenciamento de Cidades

\title{
BETWEEN METROPOLIS: JUNDIAÍ CITY
}

\begin{abstract}
Located between the two largest Brazilian cities, São Paulo and Campinas and part of São Paulo Macrometropolitan Area, the Urban Cluster of Jundiai City is recognized for its dynamism and socialeconomic importance. This is one of the few regions of the state of São Paulo who still suffers population growth due to migration. The population pendularity indices show that Jundiai is a major job generation hub for skilled labor. Started in the 80 's through the decentralization of the industrial city of São Paulo this process altered the profile of industrial jobs and generated new population attraction centers and new and complex demands. And the housing Market is the main protagonist here. At the main central areas we see the verticalization process trough condominiums dividing the city and creating islands of wealth. In contrast, the subdivision of properties located on the fringes of the city promote the spreading of the periphery which goes beyond the territorial limits of the municipality and invades the neighboring territories subjecting the worker to long commutes inside the city and sometimes even between cities. Therefore, the obvious changes in the urban expansion process in the Urban Cluster of Jundiai do not represent rupture in socio- territorial organization. Instead it consolidate trends expressed in the Metropolitan Region of São Paulo since its formation, jutting out the continuous process of tearing the urban fabric through its territory hierarchy established by socioeconomic dynamics with its physical-spatial consequences
\end{abstract}

KEY-WORDS: Macrometropolitan; Urban; Dispersion; Pendularity; Housing.

\section{ENTRE METROPOLIS: CIUDAD DE JUNDIAÍ}

\section{RESUMEN}

Situado entre las dos ciudades más grandes de Brasil, São Paulo y Campinas y parte de São Paulo Macrometropolitan Area, el Cluster Urbano de Jundiaí es reconocida por su dinamismo e importancia socio-económica. Esta es una de las pocas regiones del estado de São Paulo que todavía sufre el crecimiento de la población debido a migration. The población índices pendularidad muestran que Jundiai es un importante centro de generación de empleo para la mano de obra calificada. Iniciado en los años 80 a través de la descentralización de la ciudad industrial de São Paulo este proceso altera el perfil de los empleos industriales y generó nuevos centros de atracción de población y las demandas nuevas y complejas. Y el mercado de la vivienda es el protagonista aquí. En las principales zonas centrales vemos los condominios valle proceso de verticalización que divide la ciudad y la creación de islas de riqueza. En contraste, la subdivisión de predios ubicados en la periferia de la ciudad a promover la difusión de la periferia que va más allá de los límites territoriales del municipio e invade los territorios vecinos someter al trabajador a largos desplazamientos dentro de la ciudad y, a veces incluso entre ciudades. Por lo tanto, los cambios evidentes en el proceso de expansión urbana en el Cluster Urbano de Jundiaí no representan ruptura en socio-organización territorial. En su lugar, la consolidación de las tendencias expresadas en la Región Metropolitana de São Paulo desde su 


\section{Revista Nacional de \\ Gerenciamento de Cidades}

formación, sobresale el proceso continuo de desgarrar el tejido urbano a través de su jerarquía territorio establecido por la dinámica socioeconómica con sus consecuencias físico-espaciales

PALABRAS-CLAVE Macrometropolitan; Urbano; Dispersión; pendularidad; Vivienda.

\section{1- Introdução}

Localizado entre São Paulo e Campinas, o Aglomerado Urbano de Jundiaí, tem se destacado por sua expansão urbana descontínua através das novas formas de produção do espaço que, em muitos casos, ampliam os processos de segregação e fragmentação socioespacial desse território.

A descontinuidade compreendida como resultante das relações entre processo econômico e formas espaciais tem, na legislação, o amparo legal para a implementação de modelos de parcelamento do solo que consolidam essa tendência. Organizada a partir de um núcleo urbano principal, a expansão urbana dispersa ultrapassa os limites divisórios do município e tem como protagonista desse processo a atuação do Segmento Habitacional do Mercado Imobiliário.

\section{2 - Aglomeração Urbana de Jundiaí - Vetor de Unificação Entre Metrópoles}

Composta por sete municípios, a AU de Jundiaí é a menor dentre todas as regiões que fazem parte da Macrometrópole Paulista, entretanto essa poderosa conexão de fluxos viários, ferroviários e aeroviários que estruturam a sua espacialização, tornou-se um fator especialmente importante de promoção da dispersão e fragmentação urbana entre metrópoles.

Registrando a maior média de crescimento populacional da Macrometrópole, com volumes de movimentos pendulares internos proporcionais aos observados nas principais Regiões Metropolitanas do Estado, apresenta-se como um território denso, mas descontínuo, de áreas urbanizadas e articulado, de forma heterogênea, pela intensificação do fluxo de pessoas, mercadorias e informações, formando, 


\section{Revista Nacional de}

Gerenciamento de Cidades

muitas vezes, espaços fragmentados e policêntricos, de acordo com os atrativos específicos dispostos no território.

Os dados do IBGE ${ }^{3}$ demonstram que no AU de Jundiai, entre 1991 e 2010, a sua população total cresceu mais de $50 \%$, muito embora a intensidade média anual tenha se reduzido ao longo do período; de fato, a taxa média anual de crescimento demográfico passou de $2,47 \%$ ao ano, entre 1991 e 2000, para 1,88 a.a., entre 2000 e 2010. Vale notar, ainda, que o crescimento no período analisado foi, em grande parte, sustentado pelos municípios do entorno de Jundiaí, que respondiam por $38,0 \%$ da população da $\mathrm{AU}$, em 1991, e passaram a representar 47,0\%, em 2010, destacando-se Itupeva e Louveira com taxas de crescimento acima dos $4 \%$ ao ano, durante o período.

Das áreas que mais crescem na Macrometrópole Paulista, a Aglomeração Urbana de Jundiaí é o centro de um vetor de expansão que concentra vários municípios com grande crescimento que se estende do entorno de Campinas até a faixa norte/oeste da Região Metropolitana de São Paulo.

De maneira geral, o que se observa é que, para os períodos analisados, a migração vem perdendo importância para explicar o crescimento da população nas regiões da Macrometrópole. Essa tendência é mais acentuada na Região Metropolitana de São Paulo, entretanto, em algumas áreas, a migração ainda figura como protagonista, como nos casos da Região Metropolitana de Campinas e do Aglomerado Urbano de Jundiaí, regiões nas quais o peso relativo desse componente fica próximo de $50 \%$.

Com relação à inter-relação e complementariedade existente entre as regiões, embora o crescimento do fenômeno da pendularidade seja um indicador desse processo, os dados sobre migração sugerem que tal interação altere, na sua incorporação ao universo, o mercado de terras para fins habitacionais em outras

${ }^{3}$ Fonte: IBGE. Censo Demográfico de 1991, 2000 e 2010. Fundação SEADE. Informações do registro civil. 


\section{Revista Nacional de}

regiões da Macrometrópole. Uma assertiva nesse sentido é facilmente observada por meio do crescimento e da ocupação do solo, por exemplo, de áreas como as do eixo São Paulo-Campinas formado pela via Anhanguera.

No entanto, a região já não cresce com a mesma intensidade do passado, sendo que de um patamar de quase $2 \%$, nos anos 1990 , passa para $1,1 \%$, na década de 2000. Tal comportamento se repete em praticamente todas as regiões da Macrometrópole Paulista.

Interessante notar que, diferentemente da cidade de São Paulo e Campinas (sedes da RMSP e RMC), cujos crescimentos foram abaixo da média da Macrometrópole, a cidade de Jundiaí tem crescimento populacional bem superior, sendo o centro de um vetor de expansão que concentra vários municípios com crescimento - superior ao dobro da média verificada entre as cidades que compõem a Macrometrópole.

\section{A migração no AU Jundiaí - Perfil, Fluxos e Volumes}

Fica muito claro que aos poucos vai se formando uma nova mancha demográfica entre as regiões, particularmente entre a Região Metropolitana de São Paulo, a Região Metropolitana de Campinas e a Região Metropolitana da Baixada Santista, muito embora se saiba que, por condições geográficas, essa 'mancha' não se configura efetivamente no caso da Região Metropolitana de São Paulo e da Região Metropolitana da Baixada Santista; há poucas dúvidas, no entanto, que um processo de conurbação já se configura em direção ao norte de São Paulo rumo a Campinas, passando pela Aglomeração Urbana de Jundiaí.

Nesse sentido, o Gráfico 1 desvenda a composição dos imigrantes segundo origem em cada região. Em primeiro lugar, nota-se que, do total de migrantes registrados pelos Censos Demográficos de 2000 e 2010 nos municípios da Macrometrópole, mais de $40 \%$ apresentavam como origem outros estados, sendo que outra parcela importante destes (por volta de $33 \%$ ) fez apenas movimentos 


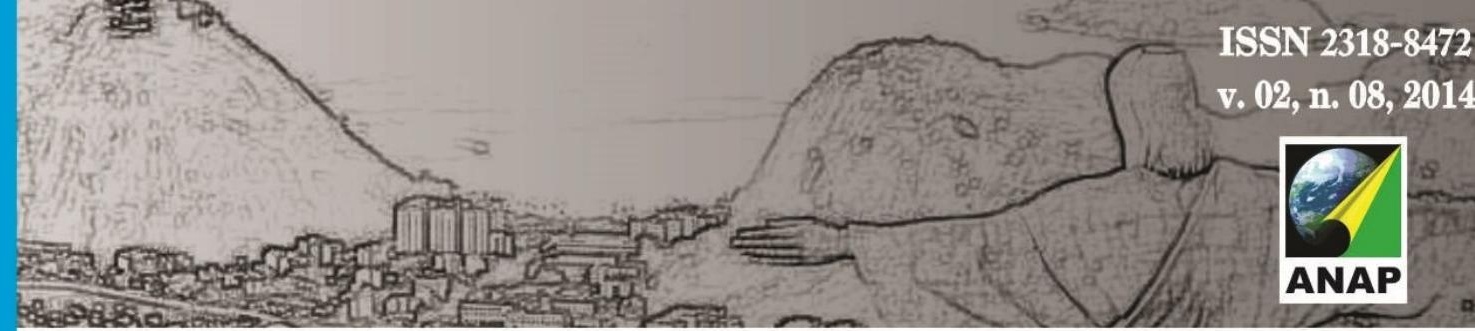

Revista Nacional de

Gerenciamento de Cidades

dentro de sua própria região. Percebe-se assim que, tanto a migração entre regiões da Macrometrópole, quanto aquela proveniente de outras regiões do Estado de São Paulo ainda representam pequena parcela na migração municipal registrada. No entanto, é importante registrar que a migração intra-regional se constitui como uma das principais tendências de mobilidade espacial nessa grande região.

$\mathrm{Na}$ visão de Nestor Goulart ${ }^{4}$, esta situação se caracteriza, basicamente, pelas condições de alta mobilidade oferecidas à população.

Grande parte das pessoas desenvolve suas vidas em dois ou três municípios, de tal forma que o município central torna-se a referência financeira, de serviços, de comércio especializado, ou seja, o centro das decisões. Diariamente, de lá saem e para lá chegam os que trabalham, os que estudam, os que tratam de negócios

O Gráfico 1 mostra que no período de $2005-2010$ as mudanças na composição da imigração nas regiões da Macrometrópole não foram muito importantes. Contudo, algumas alterações ficam evidentes: o aumento relativo de migrantes de outras Unidades Federativas para a Região Metropolitana de Campinas e para as Aglomerações Urbanas de Piracicaba e Jundiaí, o aumento da migração intra-regional na Região Metropolitana do Vale do Paraíba e Litoral Norte, além de expressivos incrementos no peso relativo dos migrantes na Baixada Santista (de $35 \%$ para $41 \%$ ) e na microrregião de São Roque (de $49 \%$ para $61 \%$ ).

\footnotetext{
${ }^{4}$ REIS, Nestor Goulart, Notas Sobre Urbanização Dispersa e Novas Formas de Tecido Urbano, Via das Artes, 2006 São Paulo, pp. 12.
} 


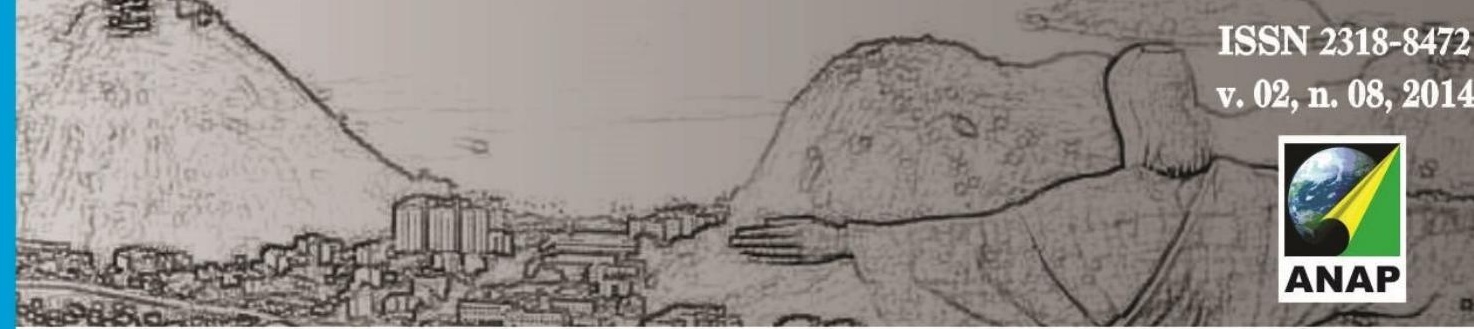

Revista Nacional de

Gerenciamento de Cidades

Gráfico 1 - Emigração por região segundo modalidade migratória - Macrometrópole Paulista 2005-2010

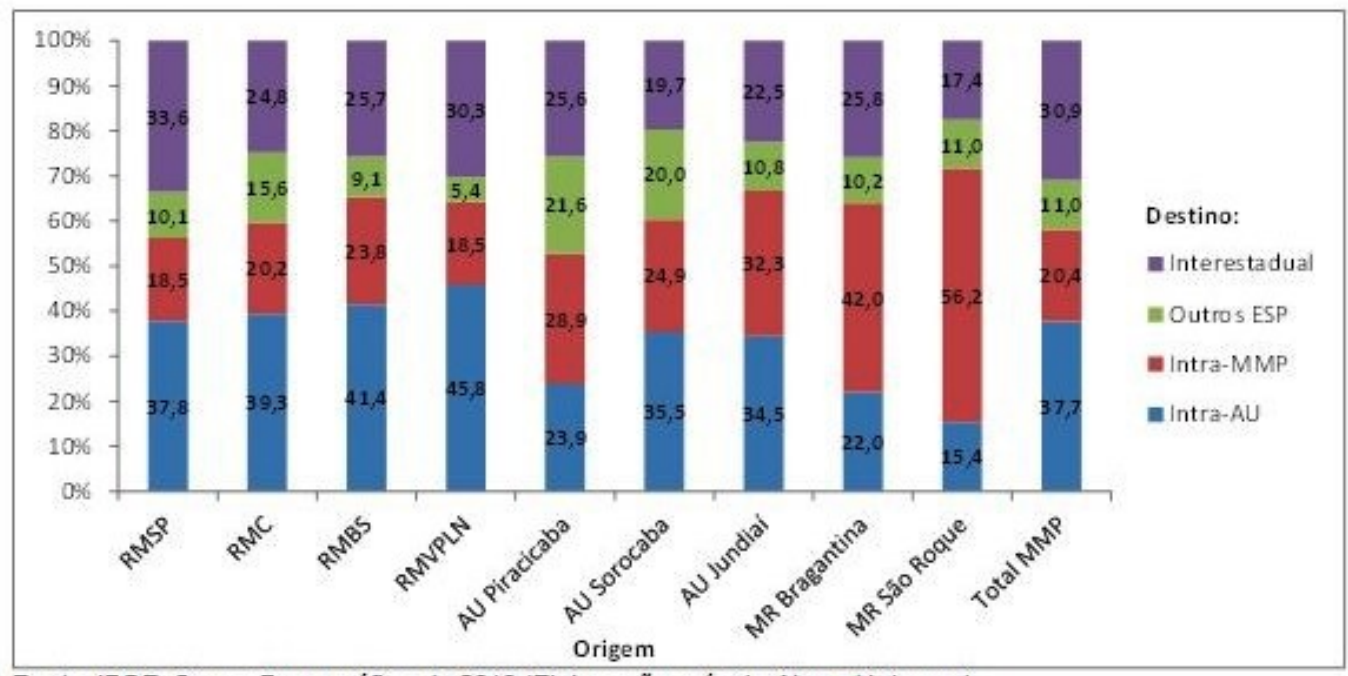

Fonte: IBGE, Censo Demográfico de 2010 (Elaboração própria, Nepe-Unicamp).

Outra análise interessante diz respeito aos fluxos intra-macrometropolitanos que podem contribuir para avaliar as relações espaciais existentes entre as regiões. Os principais fluxos migratórios ocorridos dentro da Macrometrópole podem ser visualizados no Mapa 1, onde também se verifica o papel central da Região Metropolitana de São Paulo que, em termos de trocas migratórias, visivelmente perde migrantes para as demais regiões. 


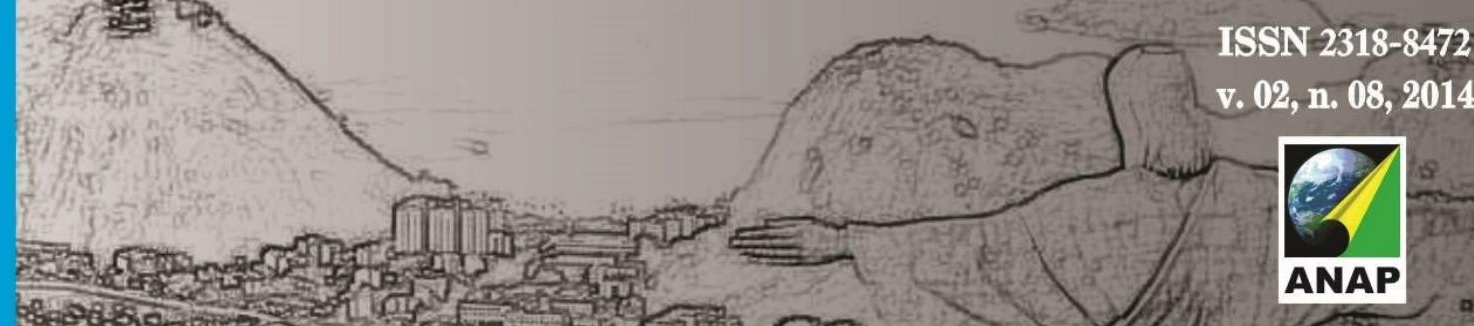

Revista Nacional de

Gerenciamento de Cidades

\section{Mapa 1 - Fluxos migratórios acima de 3 mil pessoas entre as regiões da Macrometrópole Paulista, 1995-2000 e 2005-2010}

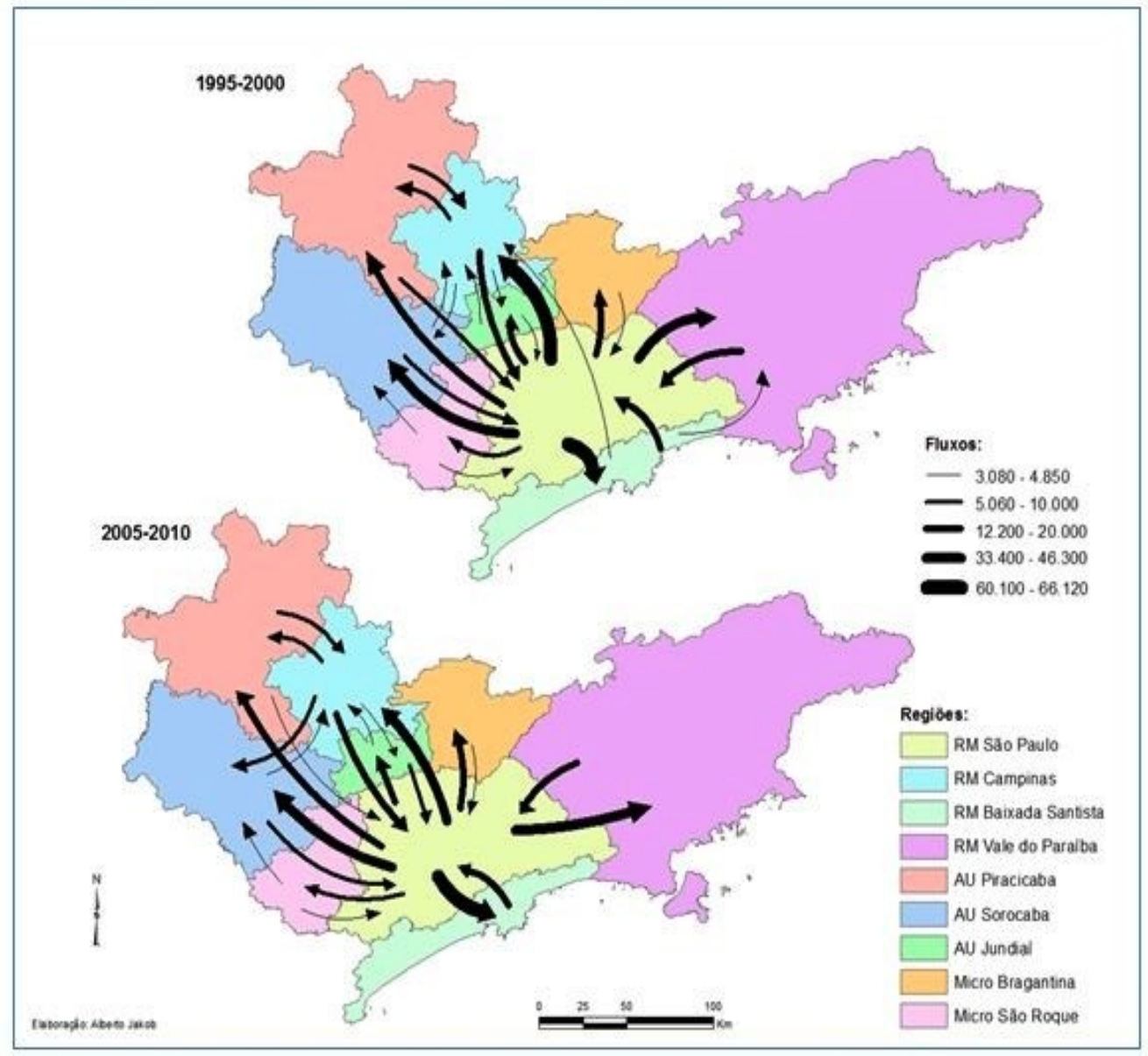

Fonte: IBGE, Censos Demográficos de 2000 e 2010 (Elaboração própria, NepQ-Unicamp).

Um primeiro resultado sugerido é o fato de que a migração com origem na própria região é, possivelmente, menos motivada por razões econômicas ou busca de trabalho, já que, em média, apenas $46 \%$ dos migrantes trabalham no mesmo município para onde se dirigiram no momento de migração. Mais que isso, quase um terço deles continuavam trabalhando no município de origem e $18 \%$ em outro município da região. Percebe-se que essa tendência, embora generalizada, é muito mais intensa nas regiões de menor porte, ou seja, nas não metropolitanas, o que 


\section{Revista Nacional de}

pode ser explicado pela maior concentração econômica existente nessas áreas nas sedes regionais.

Um dado que interessa particularmente nesse estudo diz respeito à modalidade de migração Intra-macrometrópole ${ }^{5}$. Nesse caso, em média, mais de $73 \%$ dos envolvidos trabalham no mesmo município de destino. Tal resultado sugere que os deslocamentos populacionais desse tipo denotam uma migração motivada por questões econômicas e, mais particularmente, ligada ao emprego. Apenas em algumas regiões, como Baixada Santista, Jundiaí, Bragança Paulista e São Roque, é que se registra percentual acima de $10 \%$ daqueles que continuam trabalhando no município de origem. Por esses dados, percebe-se que mais de $70 \%$ dos "nãomigrantes" ocupados em 2010 eram formados por trabalhadores manuais, ${ }^{6}$ chegando a até $84 \%$, na microrregião de São Roque. Na Região Metropolitana de São Paulo e no Aglomerado Urbano de Jundiaí estes valores foram os menores, denotando uma importante concentração de atividades não manuais e, portanto, de maior grau de qualificação. É o resultado da desconcentração industrial da São Paulo iniciada nos anos 80 do século passado e das consequentes transformações do perfil do trabalho por meio de uma forte queda dos empregos na indústria em favor de uma ascensão significativa do desenvolvimento tecnológico e do setor terciário. Estabeleceu-se um novo modelo econômico "pós-industrial", que Manuel Castells ${ }^{7}$ chega a denominar de "sociedade informacional", em contraste à sociedade industrial do período fordista.

\section{Perfil Sócio Demográfico da Mobilidade Pendular}

\footnotetext{
${ }^{5}$ Fonte IBGE, Censo Demográfico de 2010.

${ }^{6}$ NEPO, EMPLASA. (2013). O fenômeno da mobilidade pendular na Macrometrópole do Estado de São Paulo: uma visão a partir das quatro Regiões Metropolitanas oficiais. Relatório de Pesquisa, Campinas. Disponível em http://www.emplasa.sp.gov.br/emplasa/. Acesso em 17/02/2013.

${ }^{7}$ CASTELLS, Manuel. A Sociedade em Rede, Paz e Terra, 1999, São Paulo.
} 


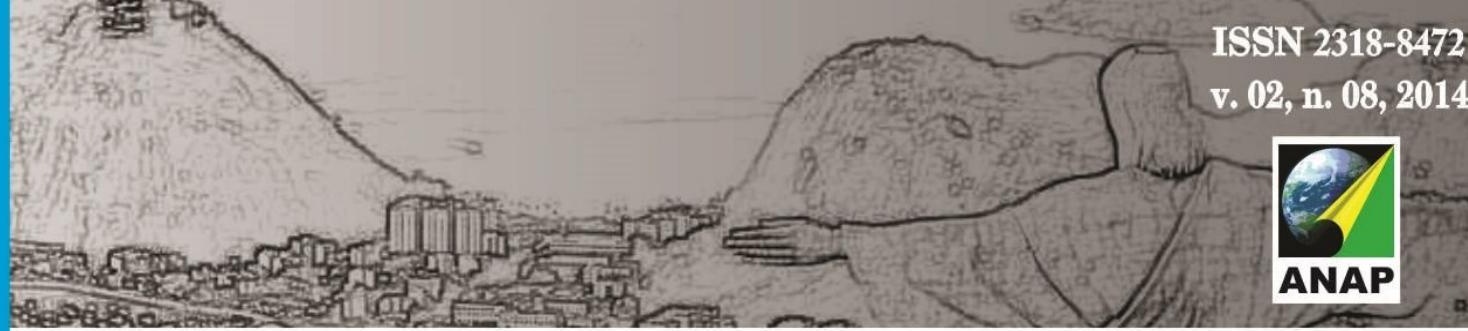

Revista Nacional de

Gerenciamento de Cidades

Segundo dados da Fundação Seade ${ }^{8}$ que demonstra a participação de cada município da aglomeração no valor adicionado regional: Jundiaí e Louveira se destacam, representando, juntas, $81,8 \%$ do total, sendo que o município sede representa mais da metade $(56,8 \%)$ do valor adicionado da região.

Quanto à evolução na última década do PIB per capita, valor adicionado e da população, percebe-se relevante crescimento nos dois primeiros para todos os municípios. O valor adicionado, neste sentido, cresceu mais do que o PIB per capita, e Louveira foi o município que apresentou maior crescimento no período, conforme Gráfico 2.

A dinâmica relativamente distinta entre os municípios desta aglomeração urbana, apresentada não se repete quando se observa a evolução da mobilidade pendular entre 2000 e 2010: com um crescimento no volume de $71,7 \%$ desse tipo de movimento, todos os municípios apresentaram aumento, fato que revela sua relevância cada vez maior no contexto regional.

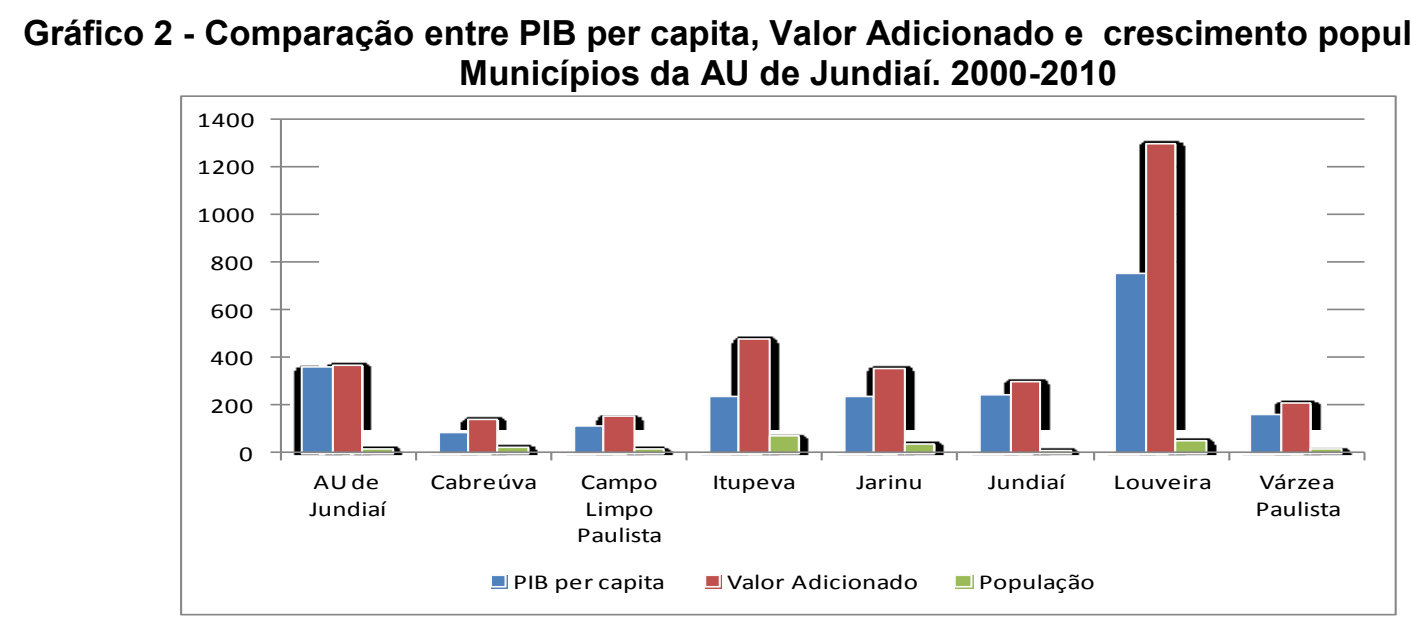

Fonte: Fundação Seade e IBGE Censo Demográfico de 2000 e 2010.

Dados do $\mathrm{IBGE}^{9}$ que se referem ao peso relativo da mobilidade pendular de residentes sobre a população em Idade Ativa (PIA) da mobilidade pendular explicita

\footnotetext{
${ }^{8}$ SEADE - Fundação Sistema Estadual de Análise de Dados

${ }^{9}$ IBGE Censo Demográfico de 2000 e 2010. (Tabulação especial, Nepo-Unicamp).
} 


\section{Revista Nacional de}

a variação do fenômeno que, em 2000, abarcava 13,1\% da PIA (população em idade ativa) total da região, passando a representar 17,6\%, em 2010. Em relação à variação entre 2000 e 2010, destacam-se os municípios de Cabreúva, Campo Limpo Paulista e Jarinu, com crescimento de mais de 7 pontos percentuais no período. Por outro lado, quando se foca a proporção dos movimentos frente à PIA total residente, em Campo Limpo Paulista com $28,7 \%$ e Várzea Paulista com 34,3\%, mostram-se os municípios mais dependentes das oportunidades existentes em outros municípios.

Com relação ao volume de indivíduos que realizam movimentos pendulares, destacam-se Jundiaí, Várzea Paulista e Campo Limpo Paulista, que, juntos, concentram $80,7 \%$ dos registrados, o que não causa surpresa na medida em que esses municípios também abrigam $79,7 \%$ da PIA total da região.

A Tabela 1, que apresenta os dados, tanto de entrada, quanto de saída de indivíduos que realizam movimentos pendulares segundo município, demonstra Jundiaí como o grande receptor regional de pendulares, concentrando $67,8 \%$ dos pendulares da própria aglomeração e $68,9 \%$ dos pendulares que vêm de outros municípios. Quando se observam os pendulares que saem do município de residência, Várzea Paulista concentra $41,3 \%$ daqueles que se dirigem para outros municípios da própria aglomeração e Jundiaí representa $62,5 \%$ dos pendulares que se dirigem para municípios de outras regiões.

Enquanto para o total das entradas o município de Jundiaí concentra $68,2 \%$ do total, quando se analisam as saídas, este município responde apenas por $34,6 \%$, influência esta que pode ser atribuída à localização entre metrópoles no Estado de São Paulo e ao maior contato dos municípios do entorno com essas outras áreas.

O que se percebe é que, aproximadamente, $60 \%$ dos pendulares de Jundiaí se dirigem para municípios das regiões metropolitanas de São Paulo e Campinas e o restante se divide em duas partes praticamente iguais entre os municípios médios e pequenos da própria aglomeração. 


\section{Revista Nacional de}

Gerenciamento de Cidades

Tabela 1 - População em Idade Ativa (PIA) e movimentos pendulares por municípios. AU de Jundiaí, 2010

\begin{tabular}{|l|c|c|c|c|c|c|c|c|}
\hline \hline \multirow{2}{*}{\multicolumn{1}{c|}{ Município }} & \multicolumn{9}{c|}{ Mobilidade Pendular } \\
\cline { 2 - 9 } & \multicolumn{2}{|c|}{ População } & \multicolumn{3}{c|}{ Entrada } & \multicolumn{3}{c}{ Saída } \\
\cline { 2 - 9 } & Total & PIA & AU Jundiaí & Outro & Total & AU Jundiaí & Outro & Total \\
\hline AU de Jundiaí & $\mathbf{6 9 7 . 6 0 4}$ & $\mathbf{5 4 9 . 5 7 1}$ & $\mathbf{6 2 . 2 9 1}$ & $\mathbf{3 4 . 3 4 9}$ & $\mathbf{9 6 . 6 4 0}$ & $\mathbf{6 2 . 2 9 1}$ & $\mathbf{3 4 . 2 2 1}$ & $\mathbf{9 6 . 5 1 2}$ \\
\hline Cabreúva & 41.525 & 30.828 & 1.531 & 1.168 & 2.699 & 3.907 & 1.577 & 5.484 \\
\hline Campo Limpo Paulista & 73.981 & 56.884 & 4.539 & 2.549 & 7.088 & 12.875 & 3.453 & 16.328 \\
\hline Itupeva & 44.658 & 33.949 & 4.383 & 1.836 & 6.219 & 4.691 & 1.076 & 5.767 \\
\hline Jarinu & 23.780 & 18.220 & 832 & 950 & 1.782 & 1.178 & 1.406 & 2.584 \\
\hline Jundiaín & 369.710 & 298.911 & 42.227 & 23.652 & 65.879 & 12.034 & 21.375 & 33.409 \\
\hline Louveira & 36.989 & 28.826 & 3.075 & 2.983 & 6.058 & 1.890 & 2.945 & 4.835 \\
\hline Várzea Paulista & 106.961 & 81.954 & 5.704 & 1.211 & 6.915 & 25.716 & 2.389 & 28.105 \\
\hline \hline
\end{tabular}

Fonte: IBGE Censo Demográfico 2010. (Tabulação especial, Nepo-Unicamp).

Verifica-se, desta forma, relevante centralidade, tanto do município sede, quanto das Regiões Metropolitanas que circundam essa aglomeração urbana.

O Gráfico 3 apresenta a escolaridade da PIA total e dos pendulares e nele se verifica, de um modo geral, que os pendulares apresentam maior escolaridade do que a PIA. Vale a pena destacar o comportamento de Jundiaí, onde os indivíduos que realizam movimento pendular apresentam maior proporção entre aqueles com graduação e pós-graduação. De fato, nesse caso a proporção daqueles com graduação chega a quase $40 \%$ do total, assim como aqueles com pós-graduação, a quase $15 \%$ do total dos pendulares. 


\section{Revista Nacional de}

\section{Gráfico 3 - Distribuição percentual da População em Idade Ativa (PIA) e dos pendulares segundo escolaridade e tipo de município de residência na AU de Jundiaí, 2010}

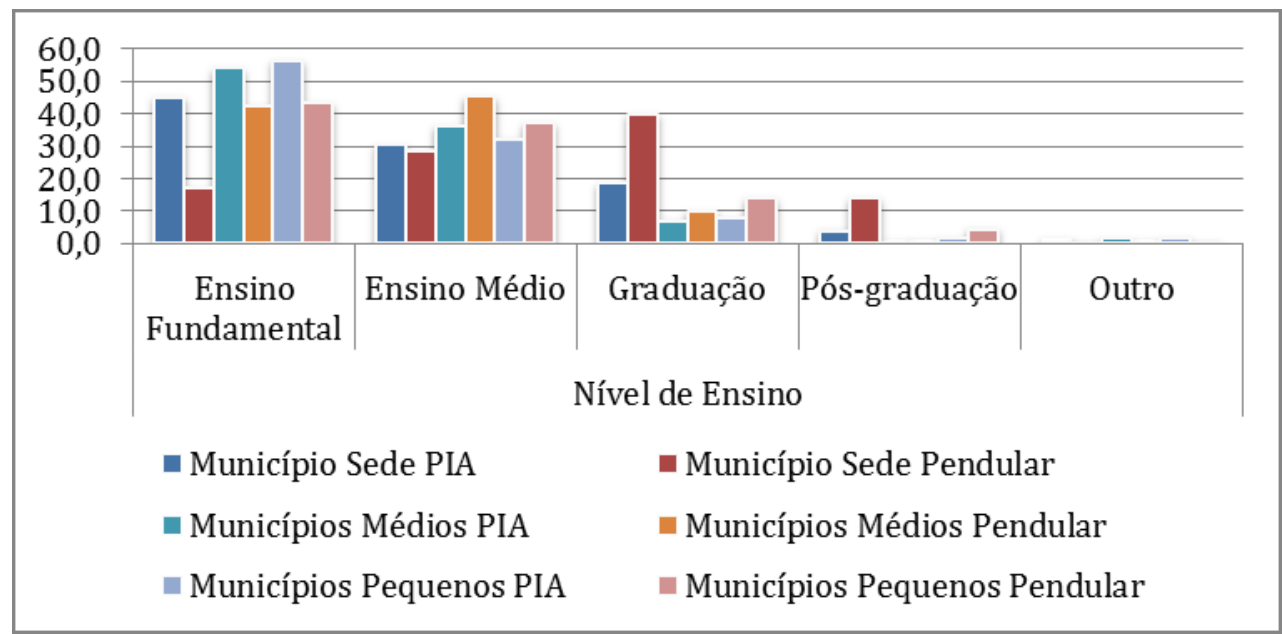

Fonte: IBGE. Censo Demográfico de 2010. (Tabulação especial, Nepo-Unicamp).

As diferenças da escolaridade apresentadas refletem ou são reflexos das áreas de atividades onde se empregam os pendulares de cada um desses municípios. Dados do Censo Demográfico de 2010 tabulados pelo Nepo-Unicamp, ${ }^{10}$ mostra as proporções segundo atividades econômicas exercidas, revela que existem diferenças expressivas entre as categorias de municípios considerados e que estes diferenciais se tornam ainda maiores quando se analisam os pendulares.

No município sede o setor de serviços é mais relevante do que nos outros, mas, de fato, as diferenças mais importantes ocorrem no setor das "indústrias de transformação", no qual os pendulares de Jundiaí têm participação relevante, e nos setores de "comércio", "construção" e "serviços domésticos", para os quais os indivíduos que realizam movimento pendular têm baixa participação, tanto quando se compara com a População Economicamente Ativa (PEA) do próprio município, quanto quando comparados com os pendulares das outras categorias de municípios.

10 NEPO, EMPLASA. (2013). O fenômeno da mobilidade pendular na Macrometrópole do Estado de São Paulo: uma visão a partir das quatro Regiões Metropolitanas oficiais. Relatório de Pesquisa, Campinas. Disponível em http://www.emplasa.sp.gov.br/emplasa/. Acesso em 17/02/2013. 


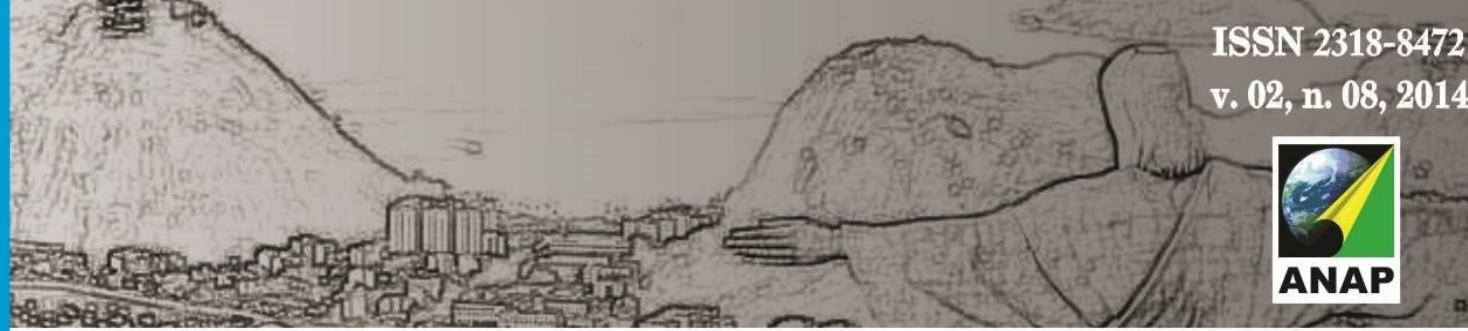

Revista Nacional de

Gerenciamento de Cidades

Acredita-se, ademais, que esses dados estão sedimentados à concentração de oportunidades em todos os níveis, do ensino ao trabalho, no município sede, o que reduz a necessidade de saída de seus residentes e acaba por atrair relevante contingente de municípios vizinhos.

Esse processo está amparado nas novas tecnologias de informação e comunicação, bem como na sua infraestrutura, sobretudo a viária, com meios de circulação automotiva moderna, individual ou coletiva, possibilitando deslocamentos entre pontos cada vez mais distantes em menor tempo.

\section{Disfunção Socioespacial Entre Trabalho e Moradia}

Os dados apresentados consolidam um modelo de expansão urbana que se caracteriza pela disfunção socioespacial entre trabalho e moradia.

Esse modelo se configura através das formas de utilização dos instrumentos para o parcelamento do solo urbano, ou seja, loteamentos e condomínios.

O loteamento é um instrumento de expansão horizontal destinado a segmentos da sociedade com menor poder aquisitivo, implantado em larga escala nas franjas da cidade e nos municípios menores, configurando-os a um perfil de cidades-dormitório. São cidades que abrigam parcelas expressivas de pessoas que se dirigem diariamente a outros municípios para atividades diversas, principalmente para trabalhar e estudar.

Os condomínios, por outro lado, destinados à classe média, localizados nas áreas urbanas consolidadas, apoiam-se em dois pilares. Primeiro, na escassez de áreas na porção consolidada das cidades. Segundo, na necessidade de otimização das áreas mais valorizadas, ou seja, produzir o maior número de unidades habitacionais possível num mesmo imóvel. 
Os dados obtidos junto ao Graprohab ${ }^{11}$ demonstram que os municípios centrais, com maior dinamismo econômico, são os municípios em processo de adensamento por meio da expansão dos condomínios verticais, forma mais visível da segregação moderna distinguindo-se das tradicionais formas de segregação por classe e por bairro.

A Aglomeração Urbana de Jundiaí entre metrópoles, tornou-se território privilegiado desse processo, o seu tecido urbano passa por grandes transformações.

O Mapa 2, demonstra através das manchas urbanas as predominância e as tendências do processo de verticalização nas Regiões Metropolitanas de São Paulo , Campinas e no Aglomerado urbano de Jundiaí.

São Paulo e Campinas são cidades com forte predominância de empreendimentos verticais implantados por meio de condomínios. Nas áreas de transição entre estas duas cidades e Jundiaí, percebemos uma predominância de ocupação horizontal, através da implantação de loteamentos.

Este mapa mostra o processo, em andamento, de unificação das manchas urbanas entre as metrópoles de São Paulo e Campinas, tendo o aglomerado urbano de Jundiaí como protagonista.

Segundo dados do Graprohab, entre 2007 e 2011, o Aglomerado Urbano de Jundiaí concentrou $6,5 \%$ do numero de empreendimentos habitacionais licenciados na Macrometropole, isso equivale a construção de 30 mil novas unidades habitacionais abrigando uma população de aproximadamente 100 mil pessoas em 2,5\% da Macrometropole, sendo que destes, apenas 7,4\% são áreas urbanas em condições legais de receberem investimentos oriundos do Segmento habitacional do mercado imobiliário

\footnotetext{
${ }^{11}$ GRAPROHAB - Grupo de Análise e Aprovação de Projetos Habitacionais do Estado de São Paulo.
} 


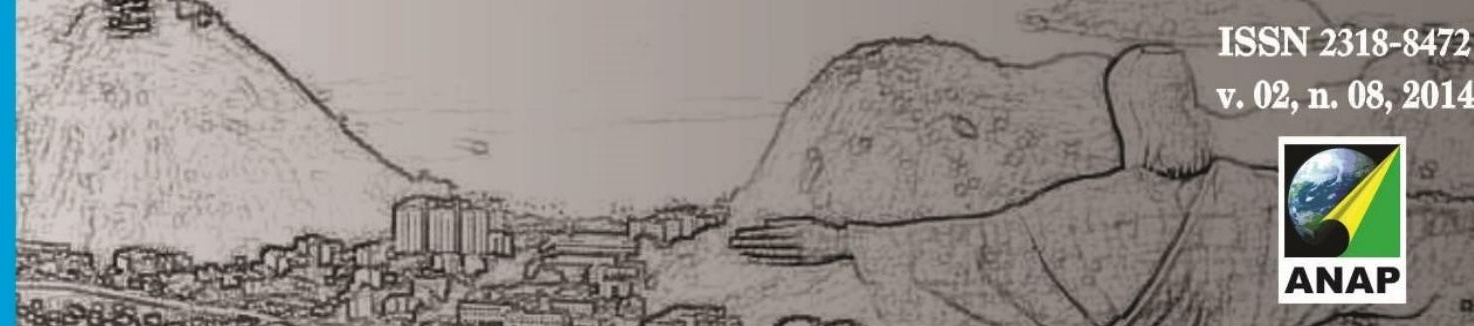

\section{Revista Nacional de}

Gerenciamento de Cidades

\section{MAPA 2 - Mancha Urbana da Predominância de Verticalização do Aglomerado Urbano de Jundiaí}

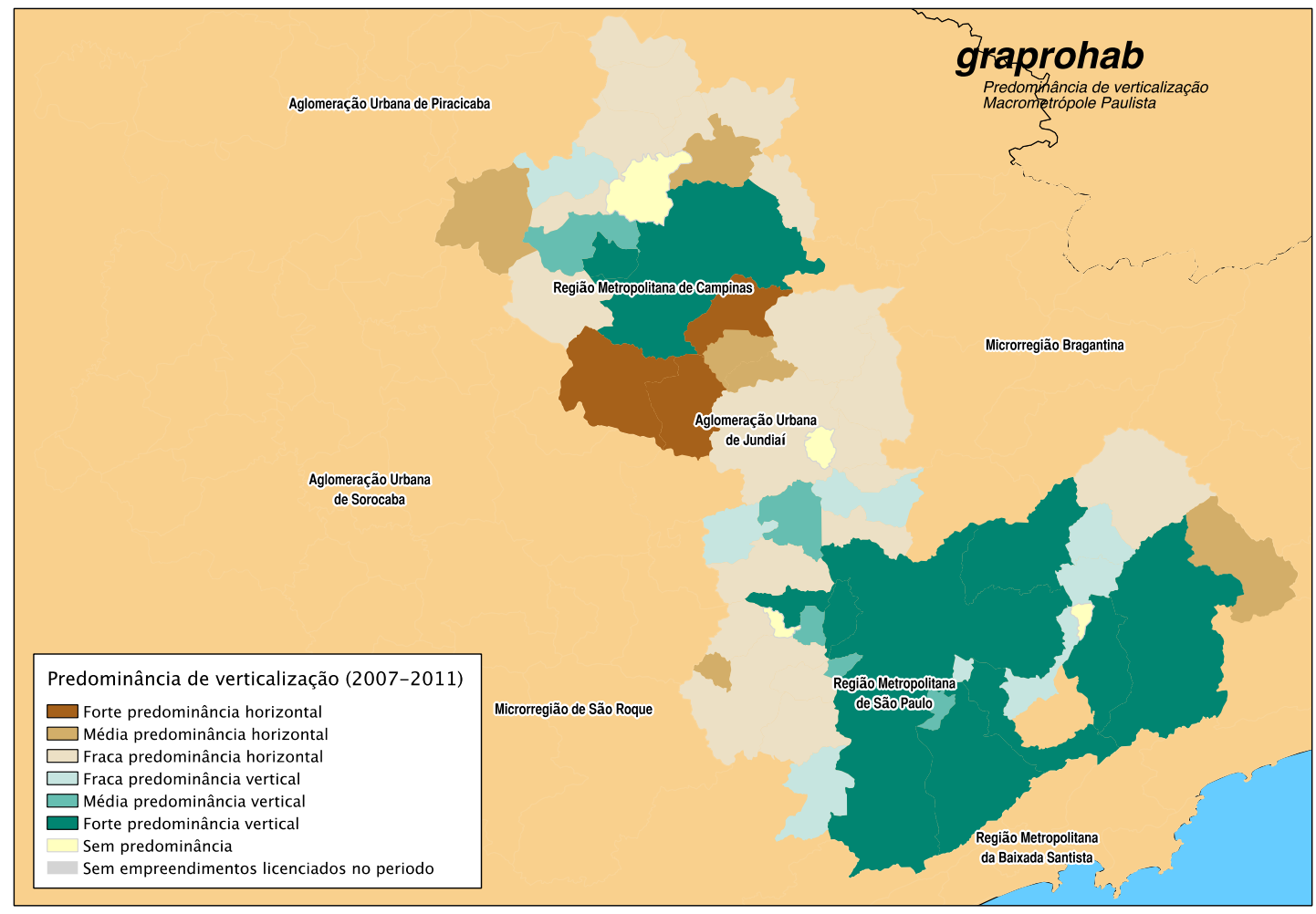

Fonte: Graprohab

Preliminarmente, entendemos que a configuração deste modelo segue o caminho da maximização da utilização e dos lucros das áreas urbanas mais valorizadas, ou seja, das áreas centrais. É nelas que se concentram a maior parte dos empreendimentos verticais, com loteamentos nas áreas mais periféricas, menos valorizadas. 


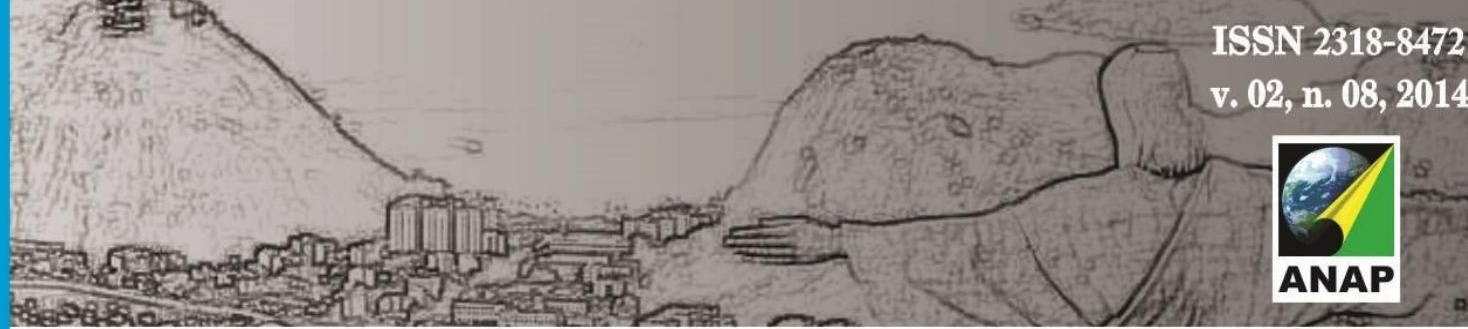

Revista Nacional de

Gerenciamento de Cidades

\section{GRÁFICO 4 - Evolução do Número de unidades habitacionais produzidas por} empreendimentos - vertical/horizontal -2007-2011

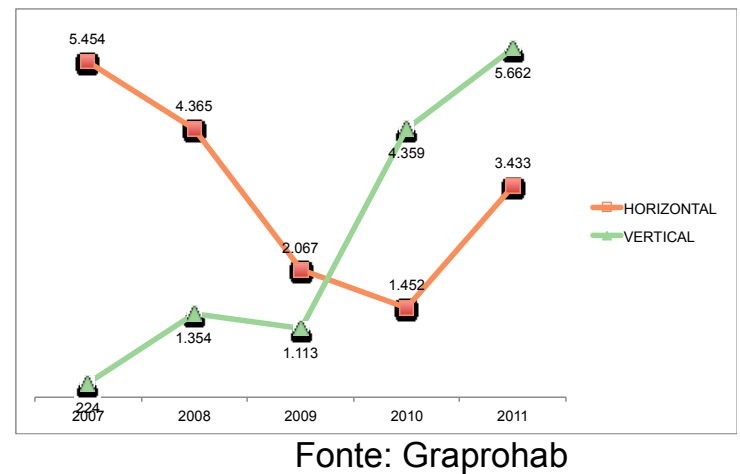

O processo da dispersão urbana demonstrado através das informações obtidas junto ao Graprohab reforça o entendimento de que o município de Jundiaí, sede do Aglomerado Urbano, passa por um processo de valorização locacional dos mais expressivos da Macrometrópole Paulista.

Suas áreas urbanas consolidadas passam por um ciclo de adensamento por meio da verticalização, confirmando seu papel de centro dinâmico do capital imobiliário.

\section{Considerações Finais}

Para Giandomenico Amendola, ${ }^{12}$

Não é a cidade, com efeito, que foi fundada, mas, sim, suas partes. A cidade estendida nasce a posteriori, como soma de partes nascidas em momentos distintos por obra de atores diferentes para populações diferentes.

Definimos Aglomeração Urbana como sendo um espaço urbano contínuo, resultante de um processo de conurbação ainda incipiente. Um espaço urbano de nível sub-metropolitano ou, em termos simplificados, uma região metropolitana de menor porte, com as áreas urbanas de duas ou mais cidades conurbadas, com fluxos e conexões econômicas, sociais e físicas que se complementam.

\footnotetext{
12 AMENDOLA, Giandomenico. La Ciudad Postmoderna: magia y miedo de La metropolis contemporânea, Madrid: Celeste Ediciones, 2000, p 27
} 
Revista Nacional de

Gerenciamento de Cidades

O Aglomerado Urbano de Jundiaí não só atende a estes quesitos, como justifica sua importância por meio de um sistema de redes entre cidades que se apoia nas dinâmicas entre as metrópoles de Campinas e de São Paulo.

Seu desenvolvimento é impulsionado por sua localização geográfica chave para as transações inter-regionais, articula ambientes culturalmente diversificados, com instituições de ensino conceituadas, polos de tecnologias de informação e sistemas produtivos importantes para São Paulo e para o Brasil.

Sedimentado na expansão urbana esse desenvolvimento tem como protagonista o segmento habitacional do mercado imobiliário que segue o modelo de ocupação dispersa baseado no parcelamento do solo, por meio de dois instrumentos: o condomínio vertical e o loteamento.

Os condomínios são implantados nas áreas urbanas consolidadas, de maior valor econômico, e tem como matriz territorial o lote, que na sua origem era ocupado por uma única residência e passa a ser ocupado por centenas de outras sem que a cidade tenha se preparado para isso.

Os loteamentos implantados nas franjas da cidade sede, Jundiaí, e nas cidades satélites, transformando-as em cidades dormitórios, são destinados a segmentos da sociedade com menor poder aquisitivo.

Portanto, se não bastassem as ilhas de riqueza localizadas na melhor parcela da cidade, com alto valor agregado, destinadas às camadas da população de maior poder aquisitivo, o espraiamento da periferia ultrapassa os limites territoriais do município, invade o território vizinho, sujeitando o trabalhador a longos deslocamentos na cidade ou mesmo entre municípios.

As alterações manifestas no Aglomerado Urbano de Jundiaí não representam ruptura na organização socioespacial, ao contrário, consolidam tendências já conhecidas e expressas na Região Metropolitana de São Paulo, sobressaindo-se o contínuo processo de esgarçamento do tecido urbano por meio da hierarquização do seu território compreendido como resultante das relações entre processo econômico e desenvolvimento urbano. 


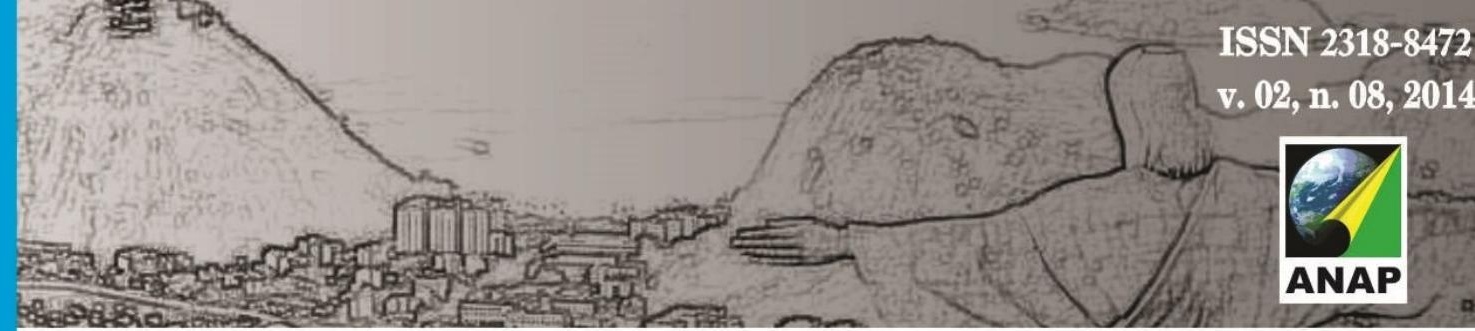

Revista Nacional de

Gerenciamento de Cidades

\section{REFERÊNCIAS}

ABRAMO. Pedro. Mercado e Ordem Urbana, Ed. Bertrand do Brasil, 2001, Rio de Janeiro.

CUNHA, Jose Marcos Pinto da. STOCO, Sergio. DOTA, Ednelson Mariano. NEGREIROS, Rovena. MIRANDA, Zoraide Amarante Itapura de. A mobilidade pendular na Macrometrópole Paulista: diferenciação e complementaridade socioespacial, Cadernos Metrópole. mobilidade urbana nas metrópoles contemporâneas, EDUC - Editora da PUC-SP, 2013, São Paulo.

CASTELLS, Manuel. A Sociedade em Rede, Paz e Terra, 1999, São Paulo.

MEYER, Regina M. Prosperi e SILVA, M.C. da, (Coord.). São Paulo Metrópole Terciária, Entre a Modernização Pós Industrial e a Herança Social e Territorial da Industrialização SP. CEBRAP, dez. 1998.

REIS, Nestor Goulart. Notas Sobre Urbanização Dispersa e Novas Formas de Tecido Urbano, Via das Artes, 2006, São Paulo.

VILLAÇA, Flavio. Espaço Intra-Urbano no Brasil, Studio Nobel Ltda., 2001, São Paulo. 